\title{
Hydrogenation of aromatic ketones, aldehydes, and epoxides with hydrogen and $\mathrm{Pd}(0) \mathrm{EnCat}^{\mathrm{TM}}$ 30NP
}

\author{
Steven V. Ley ${ }^{1}$, Angus J. P. Stewart-Liddon², David Pears ${ }^{2}$, \\ Remedios H. Perni ${ }^{*}$ and Kevin Treacher ${ }^{2}$
}

\author{
Full Research Paper \\ Address: \\ ${ }^{1}$ Department of Chemistry, University of Cambridge, Lensfield Road, \\ Cambridge CB2 1EW, UK and ${ }^{2}$ Reaxa Ltd, Hexagon Tower, \\ Blackley, Manchester M9 8ZS, UK \\ Email: \\ Steven V. Ley - svl1000@cam.ac.uk; Angus J. P. Stewart-Liddon - \\ angus.liddon@reaxa.co.uk; David Pears - david.pears@reaxa.co.uk; \\ Remedios H. Perni* - remediosperni@reaxa.co.uk; Kevin Treacher - \\ kevin.treacher@reaxa.co.uk \\ ${ }^{*}$ Corresponding author
}

Beilstein Journal of Organic Chemistry 2006, 2, No. 15 doi:10.1186/1860-5397-2-15

Received: 22 May 2006

Accepted: 25 August 2006

Published: 25 August 2006

(c) 2006 Ley et al; licensee Beilstein-Institut.

License and terms: see end of document.

\begin{abstract}
Aromatic aldehydes and ketones as well as aromatic epoxides are selectively reduced to the corresponding alcohols under mild conditions using conventional hydrogen in the presence of $\mathrm{Pd}(0) \mathrm{EnCat}{ }^{\mathrm{TM}} 30 \mathrm{NP}$ catalyst. The reactions were performed at room temperature during 16 hours with high to excellent conversions of the corresponding products.
\end{abstract}

\section{Introduction}

Benzylic alcohols occupy an important position in organic synthesis as target molecules of biological interest and synthetic intermediates that can be produced from the reduction of aromatic carbonyl substrates. Many reducing agents have been used for this purpose including metallic hydrides $\left(\mathrm{NaBH}_{4}\right.$, $\mathrm{LiAlH}_{4}$ ) and their derivatives, in addition to borane and substituted boranes, which are the most commonly used. [1-4] However, from a practical point of view a more attractive approach is to develop a selective heterogeneous catalyst that is efficient for this transformation. From an industrial perspective the economical and environmental impact of processes which replace wasteful complex hydride reagents with more weight efficient reductants such as hydrogen is considerable. Selective hydrogenation of these compounds to the corresponding alcohols is complicated by the fact that different side reactions can take place like aromatic ring hydrogenation, as well as hydrogenolysis of the produced alcohol to the hydrocarbon derivative. [5,6] Some of these problems have been circumvented by adding ethylenediamine, [7] although this can make isolation of the product and recycling of the catalyst problematic. Addition of $\mathrm{NaOH}$ or designing bimetallic catalysts in which one of the metals acts as poisoning agent, have also been reported. [8-10]

Several metals (e.g. Pd, Pt, Ru) have been used in the literature for the selective heterogeneous catalytic reduction of aryl ketones and aldehydes to the corresponding alcohols. These catalysts generally involve the use of additives to avoid the secondary reactions mentioned above, and/or the use of toxic mixed metals and in many cases high temperatures are required. [11-14] 
In previous work, colleagues at Cambridge University described the selective reduction of electron deficient and neutral aryl ketones to benzylic alcohols using Pd(0)EnCat ${ }^{\mathrm{TM}}$ $30 \mathrm{NP}$ as catalyst and a mixture of $\mathrm{HCOOH} / \mathrm{Et}_{3} \mathrm{~N}$ as the source of hydrogen [16]. Under these conditions they also achieved the chemoselective hydrogenolysis of aryl epoxides [17]. For these kind of substrates, catalysts based on Ni, Pd, and Pt have been used, and further efforts are directed toward improving the chemoselectivity and regioselectivity of this ring-opening reaction. [18,19]

We now demonstrate that aryl aldehydes and ketones as well as aryl epoxides can also effectively be reduced using $\operatorname{Pd}(0)$ EnCat ${ }^{\mathrm{TM}}$ 30NP under conventional catalytic hydrogenation conditions of $\mathrm{H}_{2}$ (atmospheric pressure) with good selectivity and conversions [20].

\section{Results and discussion}

The results obtained using different conditions for the carbonyl reduction of 4-methoxybenzaldehyde and 4-methoxyacetophenone are summarized in Table 1 . In the first case, when $\mathrm{Pd} / \mathrm{C}$ was used the over-reduced product was quantitatively obtained (entries 7 and 8). Using palladium on different supports with lower surface area than carbon, such as $\mathrm{CaCO}_{3}$ or $\mathrm{Al}_{2} \mathrm{O}_{3}$ (entries 4 and 5) a mixture of benzylic alcohol and over-reduced product was found. However, a much better selectivity was achieved when using $\mathrm{Pd}(0)$ EnCat ${ }^{\mathrm{TM}}$ 30NP. In this case, the corresponding alcohol was obtained in $94 \%-95 \%$ conversion (entries 1, 2, and 3). It is known that the use of nonprotic solvents like ethyl acetate can avoid the over-reduction of aryl aldehydes but in our experiments the same selectivity was obtained in ethanol and ethyl acetate. We have also seen minor difference in reactivity between water wet or solvent prewashed EnCat ${ }^{\mathrm{TM}}$. Solvent prewashed catalyst is slightly less active and so more selective, giving less of the over-reduced side product (entry 3 ). It is worth mentioning that the crude product obtained in Table 1, Entry 1 was analysed for metal contamination to determine the exent of leaching. Inductively coupled plasma (ICP) analysis indicated the level of palladium (in the reaction mixture after filtration) to be under $6 \mathrm{ppm}$.

In the case of 4-methoxyacetophenone the same excellent selectivity was achieved and the alcohol was obtained in $100 \%$ conversion when using Pd(0)EnCat ${ }^{\mathrm{TM}}$ 30NP under our standard conditions (entry 9). It is worthwhile mentioning that, as we expected, transfer hydrogenation conditions did not work so efficiently for this electron rich aromatic system. [17,18]

To explore the scope of this reaction, different electron rich and electron deficient aldehydes were also tested under these

Table 1: Pd(0)EnCat ${ }^{\mathrm{TM}}$ 30NP-catalyzed hydrogenation of 4-mathoxybenzaldehyde and 4-methoxyacetophenone. Comparison with other Pd catalysts.<smiles>[R]Cc1ccc(OC)cc1</smiles>

(ia) $\mathrm{R}=\mathrm{H}$

(ib) $\mathrm{R}=\mathrm{CH}_{3}$ (ii)

$\mathbf{R}$ (iii)

Entry

Method $^{a}$

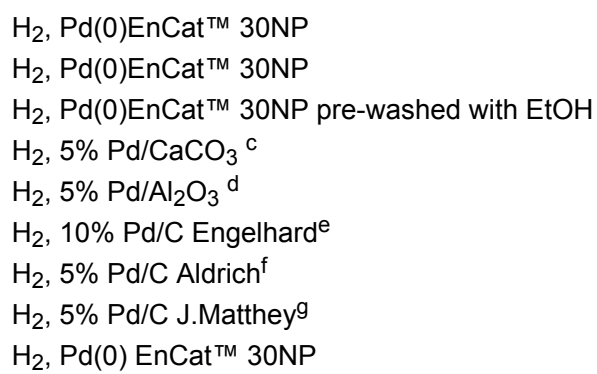

Solvent

Conversion ${ }^{b}$

(ii) $\%$

$\begin{array}{lll}\text { EtOH } & 94 & 6 \\ \mathrm{AcOEt} & 94 & 6 \\ \mathrm{EtOH} & 95 & 5 \\ \mathrm{EtOH} & 63 & 37 \\ \mathrm{EtOH} & 45 & 55 \\ \mathrm{EtOH} & 13 & 84 \\ \mathrm{EtOH} & --- & 100 \\ \mathrm{EtOH} & --- & 100 \\ \mathrm{EtOH} & 100 & ---\end{array}$

a Reaction conditions: $\mathrm{H}_{2}$ Balloon or $\mathrm{HCO}_{2} \mathrm{H} / \mathrm{Et} \mathrm{t}_{3} \mathrm{~N}, 10 \mathrm{~mol} \%$ Pdcatalyst, r.t., 16 hours. $\mathrm{Pd}(0)$ EnCat ${ }^{\mathrm{TM}} 30 \mathrm{NP}$ is supplied as a water wet solid with water content $45 \% \mathrm{w} / \mathrm{w}$. All NMR data were in agreement with the literature

b Conversions calculated by ${ }^{1} \mathrm{H}$ NMR

${ }^{c}$ unreduced dry ESCAT 1371 Engelhard

d reduced, dry ESCAT 1241 Engelhard

e $10 \% \mathrm{Pd} / \mathrm{C}$ Engelhard C3645 Aldrich ref. 520888, 3\% of aldehyde is observed

f $5 \% \mathrm{Pd} / \mathrm{C}$ Aldrich ref. 205680

g $5 \%$ Pd/C Johnson Matthey ref. 113026

${ }^{\mathrm{h}}$ see Pears, D. A.; Smith, S. C. Aldrichimica Acta 2005, 38, 24-33. 
Table 2: $\mathrm{Pd}(0)$ EnCat ${ }^{\mathrm{TM}} 30 \mathrm{NP}-$ catalyzed hydrogenation of aryl ketones and aldehydes.

Entry

Substrate ${ }^{a}$

Product

Conversion $^{b}$

1<smiles>COc1ccccc1C=O</smiles>

$100 \%$<smiles>CC(C)C</smiles>

$100 \%$

2

3<smiles>O=Cc1ccc(C(F)(F)F)cc1C(F)(F)F</smiles>

$100 \%$

4<smiles>O=Cc1ccc(F)cc1</smiles>

$87 \%$

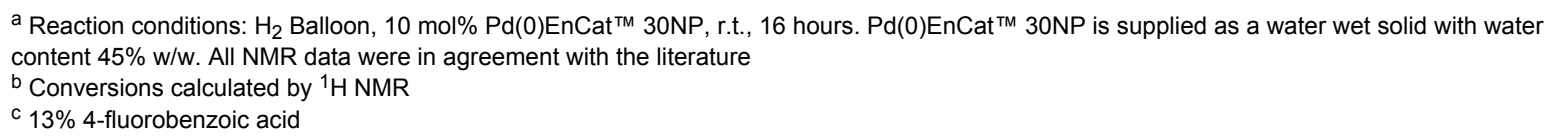

a Reaction conditions: $\mathrm{H}_{2}$ Balloon, 10 mol\% Pd(0)EnCat ${ }^{\mathrm{TM}} 30 \mathrm{NP}$, r.t., 16 hours. $\mathrm{Pd}(0) \mathrm{EnCat} \mathrm{T}^{\mathrm{TM}} 30 \mathrm{NP}$ is supplied as a water wet solid with water content $45 \% \mathrm{w} / \mathrm{w}$. All NMR data were in agreement with the literature

${ }^{b}$ Conversions calculated by ${ }^{1} \mathrm{H}$ NMR

c $13 \%$ 4-fluorobenzoic acid

standard conditions using $\mathrm{Pd}(0)$ EnCat $^{\mathrm{TM}} 30 \mathrm{NP}$ as a catalyst. In general good conversions to the corresponding benzylic alcohol were obtained. The results are summarized in Table 2.

trans-Stilbene oxide was chosen as a model for the hydrogenolysis of aromatic epoxides. The effect of different heterogeneous palladium catalysts and their propensity to over-reduce the benzylic alcohol generated after hydrogenolysis of the epoxide was investigated. In this case similar encouraging results were obtained (see Table 3 ). Employing $\mathrm{Pd} / \mathrm{C}$ resulted in complete conversion to the over-reduced product (entry 3 ), however, the use of $\operatorname{Pd}(0)$ EnCat $30 \mathrm{NP}$ as supplied gives the benzylic alcohol in $93 \%$ conversion (entry 1) which is improved to a conversion of $96 \%$ when the catalyst is prewashed with ethanol (Table 3 , entry 2). In this case, transfer hydrogenation conditions using ammonium formate as a source

Table 3: $\mathrm{Pd}(0)$ EnCat ${ }^{\mathrm{TM}}$ 30NP-Catalyzed Hydrogenolysis of trans-stilbene oxide. Comparison with other Pd catalysts.<smiles>CC(C)C</smiles>

(iv)<smiles>OC(Cc1ccccc1)c1ccccc1</smiles>

(v)<smiles>c1ccc(CCc2ccccc2)cc1</smiles>

(vi)

Entry

Method $^{\mathrm{a}}$

Solvent

Conversion ${ }^{\mathrm{b}}$

(v) $\% \quad$ (vi) $\%$

$\begin{array}{lll}\mathrm{EtOH} & 93 & 7 \\ \mathrm{EtOH} & 96 & 4 \\ \mathrm{EtOH} & --- & 100 \\ \mathrm{MeOH} / \mathrm{H}_{2} \mathrm{O} & 98 & 2\end{array}$

4

$\mathrm{H}_{2}, 5 \% \mathrm{Pd} / \mathrm{C}$ Aldrich ${ }^{\mathrm{C}}$

$\mathrm{MeOH} / \mathrm{H}_{2} \mathrm{O}$

2

a Reaction conditions: $\mathrm{H}_{2}$ Balloon or $\mathrm{HCO}_{2} \mathrm{NH}_{4}, 10$ mol\% catalyst, r.t., 16 hours. $\mathrm{Pd}(0)$ EnCat ${ }^{\mathrm{TM}} 30 \mathrm{NP}$ is supplied as a water wet solid with water content $45 \% \mathrm{w} / \mathrm{w}$. All NMR data were in agreement with the literature

${ }^{b}$ Conversions calculated by ${ }^{1} \mathrm{H}$ NMR

c $5 \% \mathrm{Pd} / \mathrm{C}$ Aldrich ref. 205680. 


\begin{tabular}{|c|c|c|c|}
\hline Entry & Substrate $^{a}$ & Product & Conversion $^{b}$ \\
\hline 1 & & & $100 \%$ \\
\hline 2 & & & $100 \%$ \\
\hline 3 & & & $100 \%$ \\
\hline 4 & & & $100 \%$ \\
\hline \multicolumn{4}{|c|}{$\begin{array}{l}\text { a Reaction conditions: } \mathrm{H}_{2} \text { Balloon, } 10 \mathrm{~mol} \% \mathrm{Pd}(0) \text { EnCat }{ }^{\mathrm{TM}} 30 \mathrm{NP} \text {, r.t., } 16 \text { hours. } \mathrm{Pd}(0) \text { EnCat }{ }^{\mathrm{TM}} 30 \mathrm{NP} \text { is supplied as a water wet solid with water } \\
\text { content } 45 \% \text { w/w. All NMR data were in agreement with the literature } \\
\text { b Conversions calculated by }{ }^{1} \mathrm{H} \text { NMR }\end{array}$} \\
\hline
\end{tabular}

of hydrogen works equally well (entry 4 in Table 3 ).

Finally, different benzylic epoxides were also subjected to the same standard conditions established above and good conversions of the homobenzylic alcohol were consistently obtained (Table 4)

In a typical procedure all reactions were performed on a 1 mmol scale. The substrate was generally dissolved in $10 \mathrm{ml}$ of $\mathrm{EtOH}, 10 \mathrm{~mol} \%$ of the catalyst was added and the mixture degassed twice under vacuum (using a water pump) and refilling with hydrogen each time. The reaction mixture was left at room temperature overnight connected to a double layer balloon of hydrogen. The catalyst was then filtered off, washed with $\mathrm{EtOH}$, and the filtrate concentrated to give a crude product which was submitted for ${ }^{1} \mathrm{H}$-NMR analysis to determine the conversion. "Pre-washing" of the catalyst was as follows: The amount of wet catalyst required was weighed and then washed with the solvent in which the reaction took place.

\section{Conclusion}

In conclusion, we have found that $\operatorname{Pd}(0) \mathrm{EnCat}^{\mathrm{TM}} 30 \mathrm{NP}$ as a catalyst during hydrogenation reactions can selectively reduce aromatic aldehydes and ketones as well as aromatic epoxides to the corresponding alcohols in high conversions under mild conditions. We have also shown that $\mathrm{Pd}(0)$ EnCat ${ }^{\mathrm{TM}} 30 \mathrm{NP}$ gives better selectivities compared to $\mathrm{Pd} / \mathrm{C}$ and other supported palladium catalysts such as $\mathrm{Pd} / \mathrm{CaCO}_{3}$ or $\mathrm{Pd} / \mathrm{Al}_{2} \mathrm{O}_{3}$.

\section{Supporting Information}

\section{Supporting Information File 1}

R H Perni Supp Inf 170806.PDF contains all experimental details.

[http://www.beilstein-journals.org/bjoc/content/ supplementary/1860-5397-2-15-S1.pdf]

\section{References}

1. Seyden-Penne, J. Reductions by the Alumino- and Borohydrides; Wiley-VCH: New York, 1991.

2. Hajos, A. Complex Hydrides; Elsevier: New York, 1979.

3. Herbert, C. B.; Subba Rao, B. C. J. Am. Chem. Soc. 1960, 82, 681. doi:10.1021/ja01488a045

4. Herbert, C. B.; Korytnyk, W. J. Am. Chem. Soc. 1960, 82, 3866. doi:10.1021/ja01500a020

5. March, J. In Advanced Organic Chemistry: Reactions, Mechanisms, and Structure; Wiley Interscience, 1992; pp 442-444.

6. Hitzler, M. G.; Poliakoff, M. Chem. Commun. 1997, 1667. doi:10.1039/ a704371f

7. Hattori, K.; Sajiki, H.; Hirota, K. Tetrahedron 2001, 57, 4817. doi:10.1016/S0040-4020(01)00421-5

8. Malyala, R. V.; Rode, C. V.; Arai, M.; Hegde, S. G.; Chaudari, R. V. Appl. Catal., A 2000, 193, 71. doi:10.1016/S0926-860X(99)00442-1

9. Casagrande, M.; Storaro, L.; Talon, A.; Lenarda, M.; Frattini, M.; Rodriguez-Castellon, E.; Maireles-Torres, P. J. Mol. Catal. A: Chem. 2002, 188, 133. doi:10.1016/S1381-1169(02)00079-1

10. Masson, J.; Cividino, P.; Court, J. Appl. Catal., A 1997, 161, 191. doi:10.1016/S0926-860X(97)00068-9 
11. Zaccheria, F.; Ravasio, N.; Psaro, R.; Fusi, A. Tetrahedron Lett. 2005, 46, 3695. doi:10.1016/j.tetlet.2005.03.159

12. Zaccheria, F.; Ravasio, N.; Ercoli, M.; Allegrini, P. Tetrahedron Lett. 2005, 46, 7743. doi:10.1016/j.tetlet.2005.09.041

13. Xu, S.; He, J.; Cao, S. J. Mol. Catal. A: Chem. 1999, 147, 155. doi:10.1016/S1381-1169(99)00140-5

14. Strohmeier, W.; Weigelt, L. J. Organomet. Chem. 1978, 145, 189. doi:10.1016/S0022-328X(00)91123-9

15. Nightingale, D.; Radford, H. D. J. Org. Chem. 1949, 1089. doi:10.1021/ jo01158a018

16. Yu, J.-Q.; Wu, H.-C.; Ramarao, C.; Spencer, J. B.; Ley, S. V. Chem. Commun. 2003, 678. doi:10.1039/b300074p

17. Ley, S. V.; Mitchell, C.; Pears, D.; Ramarao, C.; Yu, J.-Q.; Zhou, W. Org. Lett. 2003, 4665. doi:10.1021/ol0358509

18. Schultze, L. M.; Chapman, H. H.; Dubree, N. J. P.; Jones, R. J.; Kent, K. M.; Lee, T. T.; Louie, M. S.; Postich, M. J.; Prisbe, E. J.; Rohloff, J. C.; Yu, R. H. Tetrahedron Lett. 1998, 39, 1853. doi:10.1016/S00404039(98)00131-2

19. Park, G. J.; Fuchs, R. J. Org. Chem. 1957, 93. doi:10.1021/ jo01352a615

20. Broadwater, S. J.; McQuade, D. T. J. Org. Chem. 2006, 71, 2131. doi:10.1021/jo0517904

\section{License and Terms}

This is an Open Access article under the terms of the Creative Commons Attribution License

(http://creativecommons.org/licenses/by/2.0), which permits unrestricted use, distribution, and reproduction in any medium, provided the original work is properly cited.

The license is subject to the Beilstein Journal of Organic Chemistry terms and conditions:

(http://www.beilstein-journals.org/bjoc)

The definitive version of this article is the electronic one which can be found at:

$\underline{\text { doi: } 10.1186 / 1860-5397-2-15}$ 